Revista

Ibero-Americana

de Estratégıa

\title{
ESTRATÉGIA E OS ASPECTOS DE MONITORAMENTO/CONTROLE NOS SUBSISTEMAS ESTRITAMENTE COORDENADOS
}

\author{
STRATEGY AND ASPECTS OF MONITORING / CONTROL STRICTLY IN \\ COORDINATED SUBSYSTEMS
}

\section{LA ESTRATEGIA Y LOS ASPECTOS DE MONITOREO/CONTROL EN LOS SUBSISTEMAS ESTRICTAMENTE COORDINADOS}

\author{
Pedro Henrique de Gois \\ Mestrando em Administração pela Universidade Estadual de Maringá - UEM \\ Pesquisador do Programa de Pós-Graduação em Administração - Grupos de Ética em Organizações \\ e Estratégia e Storytelling \\ E-mail: pedrodgois@gmail.com (Brasil)
}

\section{William José Borges}

Mestrando em Administração pela Universidade Estadual de Maringá - UEM Professor da Faculdade Estadual de Ciências e Letras de Campo Mourão - FECILCAM E-mail: williamborges_88@hotmail.com (Brasil)

\section{José Paulo de Souza}

Doutor em Engenharia da Produção pela Universidade Federal de Santa Catarina - UFSC Professor da Universidade Estadual de Maringá - UEM

E-mail: jpsouza@uem.br (Brasil) 
Estratégia e os Aspectos de Monitoramento/Controle nos Subsistemas Estritamente Coordenados

\title{
ESTRATÉGIA E OS ASPECTOS DE MONITORAMENTO/CONTROLE NOS SUBSISTEMAS ESTRITAMENTE COORDENADOS
}

\section{RESUMO}

Este trabalho busca discutir a abordagem das estruturas estritamente coordenadas, arcabouço teórico desenvolvido por Zylbersztajn e Farina (1999) como uma perspectiva ampliada da firma, levandose em conta as supply chains alimentícias como uma extensão do nexo de contratos proposto por Coase (1937) e retomada por Williamson (1985). As estruturas estritamente coordenadas, conforme destacam Zylbersztajn e Farina (1999), se voltam para identificação de pontos de interesses comuns que incitam as firmas a promoverem, entre si, contratos de maneira estritamente coordenados, considerando o grau de especificidade de ativos envolvidos na transação e as forças competitivas que determinam a busca de posicionamento estratégico pelas organizações para alcançarem resultados sustentáveis superiores.

Palavras-chave: Controle; Economia dos Custos de Transação; Estratégia; Estrutura Estritamente Coordenada; Mensuração.

\section{STRATEGY AND ASPECTS OF MONITORING / CONTROL STRICTLY IN COORDINATED SUBSYSTEMS}

\begin{abstract}
This paper aims to discuss the approach structures of the strictly coordinated theoretical framework developed by Zylbersztajn and Farina (1999) as an expanded perspective of the firm, taking into account the food supply chains as an extension of the nexus of contracts proposed by Coase (1937) and taken up by Williamson (1985). The structures stand out as strictly coordinated. Zylbersztajn and Farina (1999) turn to identifying points of common interests that encourage firms to promote contracts between themselves in a strictly coordinated way, considering the degree of asset specificity involved in the transaction and the competitive forces that determine the search for strategic positioning organizations to achieve sustainable superior results.
\end{abstract}

Keywords: Control; Transaction cost economics; Strategy; Strictly Coordinated Structure; Measurability. 


\section{LA ESTRATEGIA Y LOS ASPECTOS DE MONITOREO/CONTROL EN LOS SUBSISTEMAS ESTRICTAMENTE COORDINADOS}

\section{RESUMEN}

Este trabajo pretende analizar el enfoque de las estructuras estrictamente coordinadas, marco teórico desarrollado por Zylbersztajn y Farina (1999) como una perspectiva más amplia de la firma, teniendo en cuenta las supply chains alimenticias como una extensión del nexo de contratos propuestos por Coase (1937) y retomada por Williamson (1985). Las estructuras estrictamente coordinadas, como destacaron Zylbersztajn y Farina (1999), se enfocanen la identificación de puntos de interés común que estimulan a las firmas a promover entresí, contratosde manera estrictamente coordinados, teniendo en cuenta, por un lado, el grado de especificidad de los activos involucrados en la transacción y, por otro lado, las fuerzas competitivas que determinan la búsqueda de posicionamiento estratégico por las organizaciones para alcanzar resultados sustentablessuperiores.

Palabras-claves: Control; Economía de los Costos de Transacción; Estrategia; Estructura Estrictamente Coordinada; Medición. 
Estratégia e os Aspectos de Monitoramento/Controle nos Subsistemas Estritamente Coordenados

\section{INTRODUÇÃO}

A mudança institucional e organizacional, como resultante da dinâmica de competitividade dos mercados globais, implica na necessária modificação das formas de estruturar as estratégias de atuação organizacional, em busca de eficiência e resultado. Dentre as opções de arranjo de mercado que se observam atualmente encontra-se o objeto deste estudo, as estruturas de coordenação estritamente coordenadas.

Neste trabalho, ao assumir a hipótese da necessidade de movimentos estratégicos como suporte à sobrevivência no mercado, se propõe que a teoria da Economia dos Custos de Transação (ECT) se comunica com as estruturas estritamente coordenadas, desenvolvendo entre si estratégias complementares, ou seja, através da redução dos custos de transação, via ECT, e mediante a padronização nos processos produtivos por meio das estruturas estritamente coordenadas. A busca por correlações entre as referidas teorias estimula a compreensão das estratégias que levam ao controle e ao monitoramento nos subsistemas estritamente coordenados.

Dessa forma, a ECT pretende explicar as diferentes formas organizacionais existentes no mercado, propondo uma teoria da firma. Os níveis de visualização do mercado, neste sentido, contemplam as estruturas de mercado, especialmente no tocante ao grau de integração vertical (Farina, et al., 1997). A partir desse grau de integração, é possível observar um novo campo de estudos voltados para compreensão de estruturas de mercado que se formam para manter um padrão na cadeia agroindustrial.

A observação da dinâmica de mercado para a escolha das estruturas de governança fez com que houvesse uma evolução da compreensão das estruturas estritamente coordenadas. Partindo do pressuposto que arranjos institucionais são complexos, entende-se que não é possível realizar uma análise adequada da realidade, tomando por referência os estudos isolados das transações. Destacase que os principais motivos que dificultam estas análises isoladas estão: a) as estruturas de mercado; b) a presença de transações integradas verticalmente; c) a existência de contratos com vários formatos; d) a participação de múltiplos agentes, e ainda; e) deve-se considerar a presença de mecanismos de salvaguardas contratuais (Zylbersztajn, 2009).

Neste sentido, por meio de uma análise da natureza contratual dos sistemas agroindustriais, em que se insere a importância das instituições e a relação estratégica dos agentes na formação dos contratos Zylbersztajn (2009, p. 61) propõe que as estruturas estritamente coordenadas "são arranjos organizacionais complexos, que envolvem simultaneamente muitos agentes". Tendo como premissa a necessidade de adaptação ao mercado como meio de sobrevivência na cadeia produtiva e 
a definição proposta por Zylbersztajn, surge a seguinte problemática: como estão implicados a estratégia e os aspectos de Monitoramento/Controle nos Subsistemas Estritamente Coordenados?

Para dar visibilidade a algumas dessas relações e tratar do problema de pesquisa, o artigo divide-se em seis seções. Após esta introdução, apresenta-se uma breve revisão sobre Economia dos Custos de Transação (ECT), seguida da caracterização das estruturas estritamente coordenadas. Na quarta seção, apresenta a aproximações da estratégia com as estruturas de mercado e sua representação por meio de estruturas estritamente coordenadas. Por fim, na quinta seção, conclui-se retomando os aspectos de monitoramento e controle na ECT e a estratégia em estruturas estritamente, indicando a potencialidade conceitual destes arranjos estratégicos em cadeias agroindustriais.

\section{ECONOMIA DOS CUSTOS DE TRANSAÇÃO}

$\mathrm{Na}$ perspectiva adotada pela nova economia institucional (NEI), em que há o crescente interesse de estudo sobre instituições e seu impacto econômico, se identificam importantes contribuições como de Ronald Coase (1937) e Douglass North (1991). Com o auxílio desses autores, conceitos importantes foram construídos para compreender os movimentos do mercado, a natureza contratual das firmas, bem como os interesses em salvaguardar os direitos de propriedade.

A partir deste arcabouço teórico surge um novo delineamento teórico denominado Economia dos Custos de Transação (ECT), com enfoque sob as estruturas de governança e, como indica Azevedo (2000), com a preocupação sobre as regras para conformação de estruturas de governança que fomentam as transações. Com isso, a partir dos insights apresentados por Coase no artigo The nature of the firm (1937) e, posteriormente, no artigo The problem of social cost (1960) passou-se a discutir a existência da firma e de custos associados à sua organização, apresentando a base conceitual para composição de estruturas de governança alternativas a negociação com base nas determinações de preço pelo mercado.

A Economia dos Custos de Transação se desenvolveu a partir dos estudos de Williamson (1985), quando a dimensão da existência de custos associados com as transações ganha evidência. Conforme Prado e Souza (2009, p. 20), a ECT “'[...] busca entender a origem das firmas e as formas organizacionais de produção mais eficientes [...]"' situação em que a identificação destes custos associados com a incerteza das transações evidencia a necessidade da criação de mecanismos, as estruturas de governança, para promover a máxima redução de custos na transação.

Revista Ibero-Americana de Estratégia - RIAE, São Paulo, v. 11, n. 1, p. 204-224, jan./abr. 2012. 
Na ECT, a transação em si é a unidade de análise central, sobre a qual se buscam identificar atributos e os custos associados com a concretização das práticas de negociação entre agente e principal, por meio da comercialização, troca ou compartilhamento de recursos baseados no direito de propriedade (Williamson, 1981). Ainda de acordo com Williamson (1981), a análise dos custos de transação, inserida no contexto da economia das organizações, tem como foco a eficiência, considerando quais partes da operação são realizadas interna ou externamente a organização e a racionalização dos custos associados a estes elementos.

A mensuração dos custos associados com a negociação de direitos de propriedade na teoria dos custos de transação considera as relações estabelecidas entre os diferentes negociantes, incluindo mecanismos contratuais de defesa dos direitos de propriedade, a coordenação entre as atividades organizacionais, bem como a escolha de estruturas de governança, seja via mercado, com a utilização de contratos de longo prazo, ou ainda por meio da integração vertical (Saes, 2009).

De acordo com Williamson (1985), a redução dos custos de transação define a condição pela qual o mecanismo de negociação via mercado é imperfeito. (Baumol, 1986). Mediante a identificação de especificidade de ativos pela firma considera-se a racionalidade limitada, sob a qual os indivíduos possuem um nível de informação sempre imperfeito, e o oportunismo, como forma de obtenção de lucro de terceiros, barreiras aos mecanismos de mercado (Baumol, 1986).

Dessa forma, são planejadas estruturas com níveis de salvaguarda e reciprocidade entre as partes negociantes, sendo indicadas na ECT as estruturas de governança hierárquicas e híbridas como perspectiva de proteção dos direitos de propriedade. O grau de especificidade de ativos é associado na ECT à condição de frequência com que as transações são realizadas e o nível de incerteza que se percebe num dado panorama futuro.

Ligados aos custos de obtenção de informação, a especificidade e a frequência da transação dão forma ao modelo proposto por Williamson (1985), indicando a maior propensão, proporcionalmente crescente, da utilização de estruturas de governança hierárquicas quando maior for à especificidade dos ativos.

A inserção do papel do oportunismo com a racionalidade limitada como determinantes na definição da estrutura de governança adequada para as firmas segue o que Barney e Hesterly (1996) identificam como pressupostos comportamentais e Williamson (1985 apud Prado e Souza, 2009) indicam como hipóteses comportamentais. A racionalidade limitada indica que os indivíduos agem racionalmente definidos, porém limitados até certo ponto (Williamson, 1985 apud Barney e Hesterly, 1996). Já o oportunismo é identificado como o aproveitamento do esforço de terceiros,

Revista Ibero-Americana de Estratégia - RIAE, São Paulo, v. 11, n. 1, p. 204-224, jan./abr. 2012. 
resultado da condição de racionalidade limitada pela qual o conhecimento das informações é desigualmente distribuído entre os atores.

A racionalidade limitada pode, de certo modo, incitar o comportamento oportunista, considerando que a composição de contratos e transações é de maneira geral ampla e complexa, sendo quase impossível prever todas as contingências futuras nas negociações (Williamson, 1981). O oportunismo surge em uma perspectiva de assimetria de informações, na qual o agente oportunista utiliza 'privilégios' advindo da posse de informações relevantes, bem como da exploração de contratos imperfeitos para ganhar vantagem e explorar a contraparte na transação.

De acordo com Barney, Wright e Ketchen Jr. (2001), a ECT tem foco exatamente sobre a anulação do oportunismo nas transações, indicando a necessidade de mecanismo de controle de ações desleais pela posse de posição vantajosa e de informação superior. $\mathrm{O}$ próprio desenvolvimento das formas hierárquicas e híbridas, como alternativa a estrutura de mercado pressupõe a criação de barreiras ou salvaguardas ao comportamento oportunista, de acordo com o grau de intensidade das negociações estabelecidas.

Nota-se, que a escolha da estrutura de governança adequada para firma responde ao grau de investimento específico envolvido numa transação, o que inviabiliza a forma de mercado e indica a necessidade de composição de estruturas hierárquicas ou híbridas para proteção contra perdas por comportamento oportunista.

A condição de incerteza futura é outra perspectiva que está intimamente ligada à possibilidade de oportunismo pelos agentes, considerando que a possibilidade de prever as condições futuras do ambiente em que se processam as negociações também é limitada. Conforme Azevedo (2000, p. 36) “... cientes da incompletude dos contratos, os agentes constroem estruturas de governança para lidar com as lacunas inevitavelmente presentes em contratos internos e externos às organizações". Portando, a incerteza torna a renegociação, em condições adversas no futuro, uma possibilidade constante, o que possibilita a existência de comportamento oportunista.

A precaução em relação à incerteza e ao comportamento oportunista leva a precaução pelos agentes nas transações, com a criação de mecanismos de salvaguarda nas negociações, sendo todos estes custos de transação abordados pela ECT (Langlois; Foss, 1996). Assim, a incerteza, a frequência com que ocorrem as transações e o grau de investimento específico numa dada transação são fatores centrais na definição da estrutura de governança adequada a ser usada numa dada transação (Williamson, 1991).

A escolha da estrutura de governança adequada se contrapõe a possibilidade de oportunismo, considerando o nível de risco associado ao investimento, utilizando recursos como a 
continuidade nas transações (frequência) e a reciprocidade nos investimentos para garantir, mesmo que de forma imperfeita, a possibilidade de ganhos oportunistas de terceiros.

Outro aspecto na ECT é a percepção pelas partes que transacionam da apropriação da quaserenda, fruto da ação oportunista pós-contratual. Conforme Klein, Crawford e Alchian (1978), a existência de comportamento oportunista está implícita em muitas situações onde se observa a dependência ou a relação de reciprocidade entre os agentes de uma transação. Mesmo em condições em que se estabelecem relações contratuais a imperfeição destes instrumentos, muitas vezes, se reflete na ação oportunista no futuro, gerando custos de litígio para defesa do direito de propriedade.

Muitas formas de ação do comportamento oportunista podem ser observadas, como a condição de barganha, em que uma das partes da transação tem maior poder e força acordos póscontratuais vantajosos, ou quando há especificidade de ativos envolvidos na negociação, o que gera uma dependência entre as partes ou, ainda, pela perda de eficiência injustificada como forma de forçar a renegociação contratual.

A condição imposta pela falha de regulamentação legal para garantir a execução dos contratos firmados e as salvaguardas estabelecidas na transação fortalecem a possibilidade de oportunismo (Klein; Crawford; Alchian, 1978). Os autores afirmam, entretanto, que, quando os ativos se tornam mais específicos à apropriação de quase renda é criada e os custos de contratação geralmente aumentam mais do que os custos da integração vertical.

Williamson $(1985 ; 2000)$ demonstra que essa escolha de estrutura de governança segue uma sequência envolvendo alternativas tecnológicas, com possibilidades de riscos contratuais e salvaguardas, interpretadas pelo autor como um movimento do simples para o complexo ou do mercado para hierarquia (Figura 1).

Figura 1- Simple contracting schema.

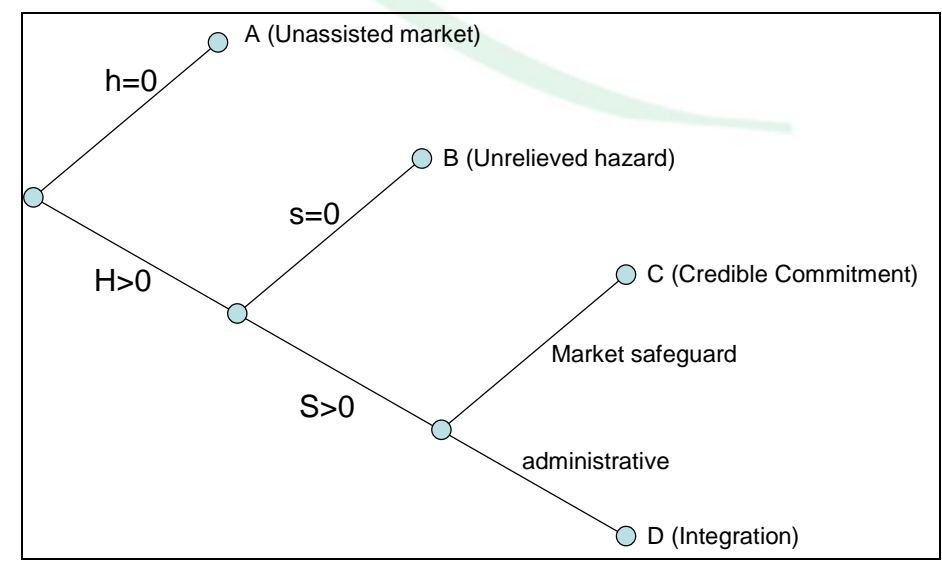

Fonte: (Williamson, 2000).

Revista Ibero-Americana de Estratégia - RIAE, São Paulo, v. 11, n. 1, p. 204-224, jan./abr. 2012. 
Na ECT, a solução contratual de longo prazo (integração vertical) é indicada como uma forma de reduzir o comportamento oportunista, composto por regras que garantam a execução da transação nos termos firmados e a repreensão legal das iniciativas oportunistas. As implicações da quebra contratual são salvaguardadas por 'prêmios', um valor adicionado à transação como forma de estímulo e garantia de que o contrato celebrado será cumprido, visando à minimização de ações oportunistas (Klein, Crawford e Alchian, 1978).

A análise dos custos de transação analisa, como é possível observar, a amplitude de transações, bem como o interesse profundo que se estabelece na compreensão de fatores comportamentais e estruturais que delineiam a composição de acordos e parcerias em arranjos produtivos.

\section{ESTRUTURAS ESTRITAMENTE COORDENADAS}

Considerando o arcabouço delineado pela Economia dos Custos de Transação, nota-se todo um esforço de pesquisa voltado ao desenvolvimento de mecanismos eficazes de coordenação das atividades produtivas, em busca de respostas imediatas e pontuais, considerando a volatilidade de ambientes fortemente competitivos e também para a redução dos custos de transação.

Tomando como base a firma como um nexo de contratos (Coase, 1937), observa-se que a atividade produtiva está baseada, primeiramente, num empreendedor, que tem em suas mãos a tomada de decisão estratégica na qual o custo associado ao uso do mercado constitui uma razão para existência da firma. Pode-se estender esta compreensão para uma realidade econômica que se desenvolve formando sistemas de fornecimento e relacionamento entre várias firmas (empreendedores). Isso desloca o papel anteriormente executado pelo empreendedor a uma complexa estrutura competitiva e dinâmica, que exige a composição de estruturas de posicionamento e respostas a pressões e interesses existentes no mercado (Williamson, 1985; Zylbersztajn; Farina, 1999).

Neste sentido, Zylbersztajn e Farina (1999) propõem, com base na teoria dos contratos de Williamson (1985), a composição de subsistemas estritamente coordenados (SSEC) para a coordenação da cadeia alimentícia de acordo com a extensão do conceito da firma como um nexo de contratos. Os subsistemas coexistem em relação a sistemas de maior complexidade, sendo compostos por firmas que atendem a diversas atividades independentes para atender a finalidade de um arranjo estabelecido de firmas (Zylbersztajn; Farina, 1999; Azevedo; Faulin, 2003). Neste 
mesmo sentido, o conceito de competitividade é ampliado, desde o nível da firma até a concorrência entre diferentes subsistemas (Zylbersztajn; Farina, 1999).

Deve-se considerar, para compreensão desta proposta, a abordagem de aspectos fundamentais vinculados a relação entre os agentes que compõem os segmentos agroindustriais que servem de base para conformação de tal modelo: aspectos de coordenação das relações contratuais entre os agentes; a formação de sistemas e subsistemas estritamente coordenados e a noção de competitividade entre os agentes e entre subsistemas concorrentes.

A coordenação entre diferentes firmas nos SSEC se revela um aspecto primordial para a eficiência de um arranjo produtivo, tanto no que se refere ao fluxo de informações quanto à operacionalidade da estrutura organizacional. Considerando os atributos básicos da transação para ECT (incerteza, especificidade de ativos, incerteza) bem como seus pressupostos comportamentais (oportunismo e racionalidade limitada), essas estruturas necessitam de um forte grau de coordenação entre as firmas, permitindo que as informações circulem rapidamente, abrangendo toda a estrutura (Zylbersztajn; Farina, 1999; Azevedo; Faulin, 2003).

Lazzarini, Chaddad e Cook (2001) consideram a interdependência entre firmas como fator importante, estudando conjuntamente a abordagem de redes e as cadeias de fornecimento para a compreensão dos processos de criação de valor e para o desenvolvimento de mecanismos de coordenação entre as firmas. Neste mesmo sentido, os SSEC representam a formação de uma rede de relacionamentos fortes, por meio dos quais os agentes interagem em função do contrato, numa dependência recíproca e intensiva, voltada para uma cadeia de produção específica.

Os recursos para continuidade nas transações (frequência) e a reciprocidade nos investimentos são utilizados para garantir, mesmo que de forma imperfeita, a possibilidade de ganhos oportunistas de terceiros. As firmas que compõem uma transação em SSEC, principalmente aquelas que demandam continuidade e um maior investimento em ativos específicos, incorrem em custos consideráveis para garantir o controle do oportunismo. Os custos são gerados porque os ativos específicos dizem respeito àqueles ativos que ao serem empregados em outra atividade, que não aquela inicialmente programada, geram perdas de valor. Assim, quanto maior a especificidade do ativo, maior serão os custos de transação. Williamson (1985) faz três considerações: (1); ativos específicos são investimentos duráveis realizados em uma transação específica; (2) a continuidade do relacionamento ou utilização do ativo para sua atividade principal é valorizada; (3) as salvaguardas contratuais e organizacionais surgem para evitar que os participantes tentem realizar outra atividade que não a contratada previamente, na tentativa de lucro monopolista.

Revista Ibero-Americana de Estratégia - RIAE, São Paulo, v. 11, n. 1, p. 204-224, jan./abr. 2012. 
Da mesma maneira, considerar a formação de SSEC indica a condição necessária de coordenação entre os interesses destes agentes, representando uma forma de organização que, pela aproximação entre os agentes, reduz a condição de comportamento oportunista, porém não excluí a possibilidade de apropriação de quase-rendas e apropriação de direito de propriedade, fator que fortalece o relacionamento contratual entre as partes.

Como destacam Zylbersztajn e Farina (1999, p. 9) “A motivação para firmas estabelecerem contratos de modo estritamente coordenados é determinada pelas características das transações que prevalecem no sistema como um todo e também por pressões competitivas impostas por outros conjuntos de contratos coordenados". Assim, nos subsistemas estritamente coordenados importa compreender a noção de competitividade, quanto à capacidade de competição gerada por meio da articulação coletiva entre firmas (Azevedo; Faulin, 2003).

A noção de competitividade entre firmas e, de forma ampliada, entre diferentes SSEC integra o ambiente competitivo e estratégias de coordenação existentes nas diversas atividades desenvolvidas por estas estruturas. A competitividade em busca de ganhos futuros, sobrevivência e desenvolvimento no mercado estão implicados com a concorrência e, desta forma, com o posicionamento estratégico adotado pelas firmas para adequarem-se ao mercado em que se encontram, realizando ajustes e ações que visem ao crescimento no segmento em que atuam (Farina, 1999).

Para Farina (1999, p.6) “... os padrões de concorrência constituem as regras do jogo competitivo", ou seja, a busca por espaço e crescimento no mercado competitivo representa uma constante sobre a qual as firmas se articulam e buscam desenvolver suas estratégias. Os esforços realizados pelas firmas, na forma de investimentos em inovação e melhoramento de seus processos, são dimensionados como ação estratégica para responder da melhor maneira, de forma rápida e eficiente, as demandas do mercado e o posicionamento futuro, considerando-se, dessa forma, as vantagens competitivas como dinâmicas sob as quais as firmas se dedicam no sentido de melhoria contínua (Farina, 1999).

Se para as firmas, tomadas de forma individual, a formação de estratégias tem efeito apenas numa perspectiva de médio e longo prazo (Farina, 1999), considerando posturas tal como imitabilidade e resposta do mercado para modelos já existentes, para as estruturas estritamente coordenadas a organização de estratégias de atuação no mercado, atuando através da habilidade de vários agentes, busca associar a rapidez no fluxo de informação entre os agentes e o ajustamento destes, de forma a promover a competitividade entre diferentes subsistemas (Zylbersztajn; Farina, 1999).

Revista Ibero-Americana de Estratégia - RIAE, São Paulo, v. 11, n. 1, p. 204-224, jan./abr. 2012. 
Ao identificar o papel da coordenação e da cooperação entre firmas ou entre estruturas estritamente coordenadas torna-se possível compreender como se dão os ajustamentos e a escolhas por estruturas de governança que irão dar dinamicidade a concorrência (Farina, 1999).

Para Farina (1999), o aspecto competitivo, neste sentido, pode ser visualizado tanto horizontalmente (da firma para indústria) quanto verticalmente (da indústria para a firma). Neste sentido, o aspecto competitivo se diferencia em relação aos diferentes segmentos e quanto à densidade e ao grau de envolvimento entre as firmas, gerando variação de grau, inclusive nos mesmos segmentos, considerando o envolvimento e as especificidades dos atributos manipulados pelos agentes (Farina, 1999).

A partir desse delineamento teórico, um novo marco conceitual é traçado e com ele surge o seguinte questionamento: o que torna possível falar em estruturas estritamente coordenadas como entidades individuais, tornando possível a competição entre diferentes subsistemas?

Como exposto acima, os sistemas e subsistemas estritamente coordenados, dada a implicação entre as partes que os compõe, e a relação contratual estabelecida entre eles, torna possível uma estrutura sob a qual se trata como uma noção ampliada da firma (Zylbersztajn; Farina, 1999). Isto é possível considerando a formação de uma estrutura onde atue um grau suficiente de monitoramento sobre as firmas que constituem os subsistemas, desenvolvendo regras de comprometimento e mecanismos diversos de motivação e controle.

Considerando os sistemas de fornecimento como um nexo de contratos pode-se supor uma série de problemas discutidos em relação a condições de hold-up contratual. Quando os custos de quebra de contrato são maiores que os benefícios derivados da violação, a expectativa é que o contrato perpetue. Nesse sentido, quando há dependência bilateral, os integrantes da cadeia produtiva procuram diminuir seus custos como forma de aumentar suas vantagens competitivas no mercado. Assim, a redução dos custos de monitoramento se configura como uma das alternativas para tornar a transação mais eficiente, pois a troca de direitos de propriedade, quando regida por contratos, contempla e faz valer os interesses das partes (Zylbersztajn; Farina, 1999).

Por essa razão, tratar de diferentes subsistemas como entidades independentes envolve também a ampliação da noção da natureza das transações e do grau de formalização e/ou confiança gerado nestas estruturas. A formação de SSEC representa uma condição favorável para lidar com a especificidade de ativos e com a redução dos custos de transação, desde que se possa contar com uma estrutura institucional adequada e capaz de balancear os interesses conflitantes, administrando as especificidades de ativos, com o intuito de minimizar as incertezas e criar um ambiente de confiança no qual os agentes possam transacionar.

Revista Ibero-Americana de Estratégia - RIAE, São Paulo, v. 11, n. 1, p. 204-224, jan./abr. 2012. 


\section{ESTRATÉGIA E AS ESTRUTURAS DE MERCADO}

Ao estudar as estruturas de mercado compreende-se como a organização consegue alinhar os seus recursos internos aos externos realizando uma estratégia definida por Porter (1996) como posicionamento estratégico. Esse posicionamento se confirma no alinhamento dos atributos de transação (frequência, incerteza e especificidade dos ativos) e das estruturas de governança adotadas, considerando os pressupostos comportamentais apontados por Williamson (1985).

$\mathrm{O}$ alinhamento estratégico deve considerar tanto os aspectos internos da firma que representam vantagem competitiva e diferenciação localizada quanto àqueles elementos externos determinados pela indústria. Isso porque a abordagem é integradora, ou seja, a análise é sistêmica e para adequar qual melhor estratégica de governança.

Para Jank, Farina e Galan (1999), a adoção da estrutura de governança adequada e um correto alinhamento das ações organizacionais traduzem-se em ganho de eficiência e competitividade, pois o posicionamento da organização é sensível à regulamentação e a dinâmica de um mercado competitivo.

O posicionamento das empresas em relação ao ambiente em que estão inseridas atua de forma pontual no delineamento de mecanismos que irão compor sua estrutura de governança, considerando quais aspectos irão compor a estratégia adotada para se posicionar frente ao mercado competitivo e a sua posição nesse jogo. Dessa forma, a relação entre a organização e mercado insere noção de estratégia competitiva, havendo nessas relações concessões e oportunidades entre os 'jogadores' na disputa por espaço e representatividade como estratégia aplicada aos mercados (Saes, 2009).

Ainda conforme Saes (2009), o modelo porteriano para o planejamento estratégico representou um grande avanço para a estruturação dos componentes metodológicos que constituíram a estrutura da indústria moderna. Com base no modelo de Porter, a busca pelo posicionamento diferenciado no mercado, superando as barreiras e buscando a diferenciação no mercado, determinam o posicionamento competitivo da empresa ou do produto frente ao mercado competitivo.

A estrutura da economia dos custos de transação (ECT) permite visualizar a forma pela qual a organização irá estabelecer sua posição em relação ao mercado. Neste sentido, as firmas podem optar por manter uma relação junto ao mercado baseada nos preços (mercado), por meio da composição de acordos formais (contratos) ou, ainda, buscar a ampliação do limite da firma (integração vertical), inserindo atividades a sua estrutura, quando os custos relacionados assim o forem mais vantajosos (Williamson, 1985; Saes, 2009).

Revista Ibero-Americana de Estratégia - RIAE, São Paulo, v. 11, n. 1, p. 204-224, jan./abr. 2012. 
A coordenação está relacionada com a organização das estruturas que compõe a ECT na busca de vantagem em posicionamento no ambiente competitivo e nos custos associados à atividade (Azevedo, 2003). O posicionamento estratégico buscado pelas firmas, nesse sentido, visa dar sustentação a vantagem competitiva conquistada por meio da adaptação ao longo do tempo e considerando a perspectiva dinâmica e em constante alteração dos mercados (Teece; Pisano; Shuen, 1997).

O enfoque estratégico, trabalhado por Teece, Pisano e Shuen (1997) e corroborado pelos estudos de Azevedo (2000) evidencia a efetividade estabelecida na complementaridade entre a coordenação e o posicionamento estratégico dos agentes que formulam tal coordenação. Isso dá visibilidade à noção ampliada da firma, inserindo o contexto econômico na análise das possíveis formas de governança.

A ampliação do conceito de coordenação aplicado à cooperação entre firmas, no âmbito da ECT, insere a discussão acerca das estruturas estritamente coordenadas.

A coordenação estrita, por meio de contratos, amplia os mecanismos de coordenação interfirmas, sendo os SSEC baseados na ECT, com foco na redução de custos de transação e garantia nos direitos de propriedade. Nesse tocante, os aspectos de monitoramento/controle inseridos na dimensão teórica da ECT permitem analisar aspectos estratégicos nos SSEC e as vantagens inerentes a este arranjo organizacional.

\section{ASPECTOS DE MONITORAMENTO/CONTROLE NA ECT E ESTRATÉGIA EM ESTRUTURAS ESTRITAMENTE COORDENADAS}

Considerando as firmas organizadas no formato de estruturas estritamente coordenadas, como exposto acima, a evidência dos aspectos de monitoramento e controle nestas estruturas se apresenta de modo relevante (Azevedo; Faulin, 2003). O alto custo de coordenação dos sistemas compostos por firma viabiliza os subsistemas estritamente coordenados em busca do controle dos atributos de transação.

Para Barzel (2005), a mensuração deve ser entendida como uma forma particular de informação. Da mesma forma que existem informações mensuráveis há que se considerar aquelas cuja mensuração só é possível durante a atividade, dificultando a utilização de contratos. Uma forma de considerar a mensuração nas relações de mercado é a efetivação de contratos de longo prazo, mantendo salvaguardas contratuais que devem ser mensuráveis e verificáveis para todos os participantes da transação. Entre as modalidades contratuais possíveis estão às formas de integração

Revista Ibero-Americana de Estratégia - RIAE, São Paulo, v. 11, n. 1, p. 204-224, jan./abr. 2012. 
vertical e horizontal que poderiam contribuir com a disseminação de informações e facilitar, portanto, a mensuração.

De forma complementar Alchian e Demsetz (1972, p. 777) afirmam que “... contratos de longo prazo entre agente e principal não são a essência do que nós chamamos de firma”. Para os autores, a firma existe porque neste espaço organizado se concebe uma estrutura de medição e incentivos para o uso de recursos que não pertencem a um só usuário. A firma seria então percebida pelos autores na seguinte abordagem "[...] um particular dispositivo político utilizado quando uma equipe de produção está presente" (Alchian, Demsetz, 1972, p. 785).

Verifica-se, dessa forma, que a propriedade e a necessidade de monitorar caracterizam variáveis que se completam no entendimento da firma e sua dinâmica. A separação entre propriedade e controle na moderna corporação define peculiaridades tanto quanto a decisão de fazer ou comprar. A propriedade especializada, conforme Demsetz (1983), por um lado, reduz o custo que poderia se obter se o proprietário fosse também o gerente e, por outro, pode ampliar os custos de monitoramento e da estrutura organizacional. Essa decisão impacta na estruturação de custos e na escolha da estrutura de gestão. Propriedade, controle e os custos inerentes a essa decisão influenciam a escolha no alinhamento entre estrutura e atributos da transação.

A informação para Barzel (2005) se estabelece como essência para garantir direitos de propriedade, influenciando na decisão de integrar ou não as atividades, pois sem informação não há definição do que se possui. A informação tem custo para ser produzida e a aquisição de um produto caracteriza apenas uma transferência parcial de informações relacionadas, possibilitando a ocorrência de disputas, tendo em vista os erros gerados. Além disso, estabelece significado para os direitos econômicos sobre o produto, tanto em termos de padrão de processo quanto em relação à geração de valor percebido pelo agente beneficiado pela aquisição.

Para Barzel (2005), se as informações são incompletas os direitos individuais não são claramente delineados, o que acaba gerando custos adicionais (custos de mensuração). Assim "para ter efetividade, então, os contraltos necessitam ser objetivamente mensuráveis e verificáveis” (Barzel, 2005, p. 361).

A integração vertical define, para Williamson (1985), um arranjo adequado na ausência ou limitação de informações ou para sua transmissão efetiva quando envolve diferentes estágiosi. A mensuração, nesse aspecto, caracteriza, para Barzel, uma particular forma de informação.

Na proposição de Barzel (2005), a formação de organizações integradas acontece quando o custo de mensurar produtos transacionados é alto. Zylbersztajn (2005) ao observar que Barzel não considera as questões comportamentais como oportunismo, em sua análise, afirma "As dimensões 
fáceis de mensurar são contratadas, enquanto os atributos de difícil medida, que abrem espaço para a captura de valor deverão permanecer dentro da empresa. O custo de medição alto invoca a captura de valor" (Zylbersztajn, 2005, p. 6). Esse aspecto remete à definição de Barzel de que a firma é um conjunto de contratos cuja variabilidade é contratualmente garantida por um capital equivalente, e, nesse aspecto, se a transação inclui esta garantia, então ela ocorre dentro da firma, sendo parte de seu escopo.

Hart e Moore (1990) observam que a abordagem dos direitos de propriedade considera que a posse de direitos de controle é fundamental para a decisão de integrar. Conforme eles, a obtenção de lucros a partir de uma segunda firma (profit stream) pode ser realizada por contratos, mas se o objetivo é ter controle precisa integrar suas atividades. Dessa forma, Zylbersztajn (2005, p. 6) conclui que “... portanto, o controle rigoroso está associado com a integração vertical, enquanto as transações de mercado são escolhidas quando a especificidade de ativos de baixa prevalece, deixando menos espaço para expropriação".

As diferentes estruturas de mercado apresentam determinantes tecnológicos como distribuição e transação que, quando combinados com as estratégias empresariais, vão resultar, segundo Farina et al. (1997), em diferentes padrões de concentração.

As estratégias empresariais identificadas podem ser de investimento em ativos específicos, na concorrência de preços, em produtos, na tomada de decisões estratégicas, entre outras estratégias. Essa decisão seria tomada, então, considerando uma estratégia similar àquela proposta por Ansoff (1965) em que a estratégia é interpretada como um conjunto de regras para a tomada de decisão em condições de desconhecimento parcial. A identificação de oportunidades futuras, a mensuração das transações integradas e as renegociações ocasionadas pelo comportamento oportunista dos agentes estariam envolvidas em uma prospecção do futuro, pois o tomador de decisão não conhece os efeitos de segunda ordem que a decisão de integração causará.

A motivação estratégia pode ser a intenção de formar uma estrutura capaz de contemplar os elos institucionais da firma, mantendo um monitoramento dos movimentos estratégicos e padronizando o comportamento dos agentes a fim de manter um fluxo contínuo das atividades da cadeia. Assim, se estabelece um alto grau de mensuração das atividades e, consequentemente, o controle da cadeia por meio de um subsistema estritamente coordenado.

Considerando tais aspectos, a formação de SSEC considera a ação conjunta do arranjo composto por firmas que se aproximam e buscam se precaver de problemas relacionados a pressões e a forças competitivas, buscando ampliar as possibilidades de respostas estratégicas na competição por mercados.

Revista Ibero-Americana de Estratégia - RIAE, São Paulo, v. 11, n. 1, p. 204-224, jan./abr. 2012. 
A estratégia subjacente à composição de SSEC representa o desenvolvimento de incentivos alinhados aos interesses das partes contratuais, adicionando mecanismos de monitoramento que permitem a todas as partes acessar informações relevantes quando necessário, além de mecanismo de monitoramento/controle para lidar com o comportamento oportunista (Zylbersztajn; Farina, 1999).

\section{CONSIDERAÇÕES FINAIS}

Tomando os subsistemas estritamente coordenados em um enfoque estratégico e dando evidência aos aspectos de monitoramento e controle associados a ECT, buscou discutir, neste ensaio, a configuração desta configuração estratégica como forma de organização de firmas com base numa proximidade de interesses e de investimentos. A especificidade de ativos e a busca por garantia dos direitos de propriedade, próprios da ECT, são pontos essenciais de implicação entre os agentes que compõem SSEC, levando-se em conta o papel de cada segmento da cadeia para a concretização dos objetivos centrais firmados como objetivo do subsistema.

Como destacado, a definição de estratégias visando à competitividade e o posicionamento de forma diferenciada em relação à concorrência conduz a busca de um posicionamento pelas firmas que lhes garanta sustentação de vantagens e novas oportunidades de desenvolvimento no futuro. A relação entre estas estratégias definidas pelas firmas e os aspectos de monitoramento e controle nas estruturas estritamente coordenadas implicam na composição de arranjos contratuais que se, por um lado, ampliam a dependência entre os agentes, por outro, fortalece os laços de comprometimento e de confiança para chegar a um modelo eficiente de atuação no mercado.

Por outro lado, a confiança não será plena, pois se deve considerar o caráter oportunista dos agentes, necessitando que existam, durante todo o processo produtivo, monitoramento e controle dos processos em que os agentes estão envolvidos. De forma similar, a noção de adaptação salienta o posicionamento estratégico que circunscreve o monitoramento e controle, corroborando a noção de incompletude dos contratos e a constante readaptação do ambiente institucional. Mediante a limitação da problemática contratual, novos estudos poderiam contemplar o funcionamento do subsistema, analisando os conflitos de interesses, enquanto fenômeno, e seus possíveis desequilíbrios inerentes às transações.

Os padrões propostos e estabelecidos se configuram como uma ferramenta utilizada para manter a capacidade competitiva. Assim, o delineamento das atividades produtivas é realizado por meio da constante prática e adaptação que se volta para a articulação do subsistema, a fim de 
melhorar o posicionamento no mercado. Se por um lado, o arranjo produtivo amplia a dependência dos agentes, por outro, os laços de comprometimento e confiança são fortalecidos, fazendo com que os agentes tenham condições de trabalhar sob o mesmo prisma, ou seja, com o mesmo objetivo.

Os subsistemas estritamente coordenados representam uma condição favorável para lidar com a especificidade de ativos e com a redução dos custos de transação, desde que se possa contar com uma estrutura institucional adequada, planejada e voltada para o gerenciamento com qualidade das diferentes partes que fazem parte destes subsistemas, atendendo aos interesses e as especificidades gerais, promovendo a confiança e o comprometimento dos agentes e a segurança por comporem tais estruturas.

A decisão de integrar as atividades da cadeia deve, portanto, considerar que a abordagem dos direitos de propriedade deve inserir em seu escopo também os direitos de controle da cadeia, tendo em vista o intuito de criar um padrão e regrar as atividades.

Esse regramento não garante o controle total dos direitos de propriedade. Embora seja de grande importância, um subsistema não é capaz de realizar o controle absoluto dos direitos de propriedade. Em consequência, se o objetivo dos agentes muda, é necessário regrar, de forma completa e integral, os direitos de propriedade, sendo a próxima etapa integrar as atividades verticalmente e administrar todo o complexo produtivo.

A ampliação do limite da firma nas estruturas estritamente coordenadas pressupõe a composição de modelos de monitoramento e controle que, de forma efetiva, correspondam à necessidade de coordenar um sistema que se torna complexo pelo encadeamento de várias atividades e que passa a ser composto por uma ampla diversidade de interesses envolvidos nas transações.

\section{REFERÊNCIAS}

Alchian, A.A; Demsetz, H.(1972) Production, information costs, and economic organization. The American Economic Review, 62, 777-795.

Ansoff, I. (1965) Estratégia empresarial. McGraw-hill, S. Paulo, 1965.

Azevedo, P.F. de. (2000) Nova economia institucional: referencial geral e aplicações para a agricultura. Agric. São Paulo, São Paulo, 47, 33-52.

Azevedo, P.F.de., Faulin, E. J. (2003) Strictly coordinated subsystems based on trust: the Case of greens. 2003. Recuperado de 10 abril 2011, de: www.pensa.org.br/anexos/biblioteca/13320071457_.pdf.

Revista Ibero-Americana de Estratégia - RIAE, São Paulo, v. 11, n. 1, p. 204-224, jan./abr. 2012. 
Barney, J.B., Hesterly, W. (1996) Organizational economics: understanding the relationship between organizations and economic analysis. In: S. Glegg, C. Hardy. D. Nord (Eds). Handbook of organization studies. London: Sagep. 115-147.

Barney, J. W. M., Ketchen, D. (2001) The resource-based view of the firm: ten years after 1991. Journal of Management, 27, 625-641. doi:10.1177/014920630102700601

Barzel, Y. (2005) Organizational forms and measurement costs. Journal of Institutional and Theoretical Economics, 161, 357-373. doi:10.1628/093245605774259291

Baumol, W.J.(1986) Williamson's the economic institutions of capitalism. Rand Journal of Economics. 17(2), 279-286. doi:10.2307/2555390

Coase, R. H. (1937) The nature of the firm. Economics, 4, 386-405.

Demsetz, H. (1983) The structure of ownership and the theory of the firm. The Journal of Law \& economics, 26, 375-390. doi:10.1086/467041

Farina, E.M.M.Q. (1999) Competitividade e coordenação de sistemas agroindustriais: um ensaio conceitual. Revista Gestão e Produção, 6(3), 147-161.

Farina, E. M. M. Q., Azevedo, P. F., Saes, M. S. M.(1997) Competitividade: mercado, estado e organizações. Editora Singular, 1997.

Hart, O., Moore, J. (1990) Property rights and the nature of the firm. The Journal of Political Economy, 98, 1119-1158. doi:10.1086/261729

Jank, M.S, Farina, E.M.M.Q., Galan, V. B. O (1999) Agribusiness do leite no Brasil. São Paulo: Milkbizz/ PENSA.

Klein, B., Crawford, R. G., Alchian, A.A.(out.1978) Vertical integration, appropriable rents, and the competitive contracting process. Journal of Law and Economics, 21(2), 297-326. doi:10.1086/466922

Langlois, R.N. Foss, N.J.(1996) Capabilities and governance the rebirth of production in the theory of economic organization. Department of Economics Working Paper Series. University of Connecticut. Dinamarca., 1-37.

Lazzarini, S.G., Chaddad, F.R., Cook, M.L.(2001) Integrating supply chain and network analysis: the study of netchains. Journal on Chain And Network Science, 1(1), 7-22. doi:10.3920/JCNS2001.x002

North, D.C. (1991) Institutions. The Journal of Economic Perspectives, 5(1), 97-112.

Revista Ibero-Americana de Estratégia - RIAE, São Paulo, v. 11, n. 1, p. 204-224, jan./abr. 2012. 
Estratégia e os Aspectos de Monitoramento/Controle nos Subsistemas Estritamente Coordenados

Porter, M. (nov-dec,1996) What Is Strategy? Harvard Business Review.

Prado, I.N. do, Souza, J.P. de. (2009) Cadeias produtivas: estudos sobre competitividade $e$ coordenação. (2. ed.) Maringá: EDUEM.

Saes, M.S.M. (2009) Estratégias de diferenciação e apropriação da quase-renda na agricultura: a produção de pequena escala. São Paulo: Annablume, Papesp.

Teece, D., Pisano, G., Shuen, A. (1997) Dynamic capabilities and strategic management. Strategic Management Journal, 18(7), 509-533. doi:10.1002/(SICI)1097-0266(199708)18:7<509::AIDSMJ882>3.0.CO;2-Z

Williamson, O.(1981) The economics of organization: the transaction cost approach. The American Journal of Sociology, 87(3), 548-577. doi:10.1086/227496

.(1985) E. The economic institutions of capitalism: firms, markets and relational contracts. New York: The Free Press.

.(1991) Comparative economic organization: the analysis of discrete structural alternatives. Administrative Science Quarterly, 36, 269-296. doi:10.2307/2393356

. (2000) The new institutional economics: taking stock, looking ahead. Journal of Economic Literature, 38, 595-613. doi:10.1257/jel.38.3.595

Zylbersztajn, D., Farina, E. M.M.Q.(1999) Strictly coordinated food-systems: exploring the limits of the coasian firm. International Food and Agribusiness Management Review, 2, 249-265. doi:10.1016/S1096-7508(00)00014-8

(2005) Measurement costs and governance: bridging perspectives of transaction cost economics. In: International Society for the New Institutional Economics - ISNIE, Barcelona-Espanha.

(2009) Papel dos contratos na coordenação agro-industrial: um olhar além dos mercados. In: Souza, J.P. de, Prado, I.N. do. Cadeias produtivas: estudos sobre competitividade e coordenação. (2. ${ }^{a}$ ed.) Maringá: EDUEM.

Revista Ibero-Americana de Estratégia - RIAE, São Paulo, v. 11, n. 1, p. 204-224, jan./abr. 2012. 


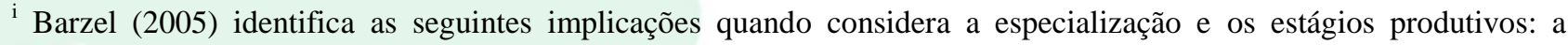
integração vertical aumenta com o número de passos verticais na produção; a produção se torna mais integrada quando o custo da organização das relações verticais cai; a produção se torna mais integrada quando os ganhos da especialização aumentam.

Recebido: 07/12/2011

Aprovado: 29/01/2012

Revista Ibero-Americana de Estratégia - RIAE, São Paulo, v. 11, n. 1, p. 204-224, jan./abr. 2012. 